\title{
NUMERICAL INVESTIGATION OF INTERCEPTOR EFFECT ON SEAKEEPING BEHAVIOUR OF PLANING HULL ADVANCING IN REGULAR HEAD WAVES
}

UDC 629.5.017.2:629.5.025:629.52

Original scientific paper

\begin{abstract}
Summary
In this paper an attempt has been made to assess the capability of numerical algorithm based on Reynolds Averaged Navier Stokes (RANS) for predicting the motion characteristics of the planing hull in calm water and regular waves. The focus of the present study is the impact of interceptors on the sea keeping quality of a planing vessel investigated through the application of numerical methods. The wave properties such as wavelength and wave height are taken into consideration to investigate the effect of wave steepness on vessel response. It is found that numerical data can efficiently simulate the motion attitude and the hydrodynamic characteristics of planing craft in regular head waves. The planing hull with and without interceptor fitted at the transom is simulated in numerical wave tank. The results show reduction in heave and pitch motions which gave favorable sea keeping behavior for the hull fitted with interceptor. The numerical solution is useful for the preliminary prediction of navigation safety during sailing.
\end{abstract}

Key words: seakeeping; RAO; CFD; regular head waves; interceptor; planing vessel

\section{Nomenclature}

\begin{tabular}{|l|l|l|l|}
\hline $\mathrm{A}_{3}$ & $\begin{array}{l}\text { Heave motion } \\
\text { amplitude }\end{array}$ & ITTC & $\begin{array}{l}\text { International Towing Tank } \\
\text { Conference }\end{array}$ \\
\hline $\mathrm{A}_{33}$ & Heave added mass & $\mathrm{I}_{\mathrm{L}}$ & $\begin{array}{l}\text { Moment of inertia of } \\
\text { waterplane }\end{array}$ \\
\hline $\mathrm{A}_{5}$ & $\begin{array}{l}\text { Pitch motion } \\
\text { amplitude }\end{array}$ & $\mathrm{I}_{55}$ & $\begin{array}{l}\text { Mass moment of inertia about } \\
\text { yais }\end{array}$ \\
\hline $\mathrm{A}_{55}$ & Pitch added inertia & $L_{p p}$ & Length between perpendiculars \\
\hline $\mathrm{A}_{\mathrm{W}}$ & Area of waterplane & $L$ & Length overall \\
\hline$B$ & Maximum Breadth & $L_{k}$ & Keel length \\
\hline $\mathrm{C}_{\mathrm{B}}$ & Block coefficient of & $m$ & Mass of vessel \\
\hline $\mathrm{C}_{\mathrm{WP}}$ & $\begin{array}{l}\text { Coefficient } \\
\text { waterplane }\end{array}$ & $\begin{array}{l}\text { Reynolds Averaged Navier } \\
\text { Stokes }\end{array}$ \\
\hline
\end{tabular}




\begin{tabular}{|l|l|l|l|}
\hline CFD & $\begin{array}{l}\text { Computational Fluid } \\
\text { Dynamics }\end{array}$ & $T$ & Draft of vessel \\
\hline $\mathrm{C}_{\mathrm{IL}}$ & $\begin{array}{l}\text { Coefficient of inertia of } \\
\text { waterplane about y-axis }\end{array}$ & $\Delta \mathrm{t}$ & Time step \\
\hline $\mathrm{C}_{33}$ & Restoring heave force & $V$ & Speed of the vessel \\
\hline $\mathrm{C}_{55}$ & Restoring pitch moment & VOF & Volume of Fluid \\
\hline $\mathrm{DFBI}$ & $\begin{array}{l}\text { Dynamic Fluid body } \\
\text { Interaction }\end{array}$ & $\zeta$ & Wave elevation \\
\hline $\mathrm{f}_{\mathrm{e}}$ & $\begin{array}{l}\text { Encounter frequency of } \\
\text { ship }\end{array}$ & $\omega_{3}$ & Heave frequency \\
\hline $\mathrm{f}_{\mathrm{n}}$ & Natural frequency of ship & $\omega_{5}$ & Pitch frequency \\
\hline $\mathrm{Fr}_{\mathrm{B}}$ & Beam Froude number & $\lambda$ & Wavelength \\
\hline $\mathrm{g}$ & Gravitational constant & $\beta$ & Deadrise angle \\
\hline$H$ & Wave height & & \\
\hline
\end{tabular}

\section{Introduction}

The high-speed planing hulls are those vessels that have predominant hydrodynamic forces at high speeds, while the buoyancy force is reduced. The hydrodynamic pressure in these vessels creates lift, which affects the trim angle of the craft. Researchers made an extensive study on the effects of different stern appendages like stern flaps, stern wedges, trim tabs, and hull vanes on planing hulls. Interceptors are appendages used successfully on high-speed vessels to operate at minimum trim conditions. An interceptor is a thin plate that is mounted at the transom surface whose sharp tip follows the shape of the transom edge in a direction perpendicular to the hull bottom surface as shown in Fig 1b. The numerical studies of Brizzolara [4] on planing hull showed that the maximum height of interceptor is usually well contained within the hull boundary layer at the transom. Suneela et al., [28] conducted numerical study on planing hull with and without interceptor. The study reported good correlation with classic study of Savitsky [32] for bare hull. High-speed planing vessels exhibit many different dynamic instability phenomena of motions in both vertical and transverse planes, such as proposing, chine walking, progressive heeling, unstable pitchinginduced rolling, or a combination of them (Ikeda and Katayama [18]). The design parameters studied include the location of the center of gravity, load, forward speed and other geometric parameters of the vessel.

In reality, ocean waves are irregular, and so analysis of ship motion in regular waves was an obvious approximation considered by researchers. Fridsma [15] conducted experiments on the planing hull with a series of constant deadrise angles for varying lengths on the effect of trim, drag, deadrise, speed, and load in smooth water and regular waves. The models are tested in regular waves at a wavelength to hull-length ratios of 1, 1.5, 2, 3, 4, and 6 with deadrise angles of 10,20 and $30 \mathrm{deg}$ and found that maximum motions occur at the wavelengths equal to three or four times the hull length.

A theoretical method was developed by Milton et al.,[23] for predicting the linearized response characteristics on planing hulls with constant deadrise in head and following waves. To compute the motions and accelerations of prismatic planing craft a computer model was developed by Zarnick [38] in irregular head waves. A vessel with deadrise angle of $20 \mathrm{deg}$, in a single sea state were computed and compared with Fridsma [15] experiments. They predicted that the craft behavior is more effective in moderate operating conditions. Wang [36] studied the effect of the stern wedge on ship powering performance of planing and semiplaning vessels. Based on modified strip theory the equations of motion for high-speed planing boat in regular waves with controllable flaps are considered in their study. $\mathrm{He}$ concluded that there is a reduction in motion amplitudes with controllable flaps at or near the 
resonant frequency. Vertical plane motions have been investigated by many researchers for years on high-speed planing hulls.

Further, $\mathrm{Xi}$ et al.,[37] presented vertical plane motions in high-speed vessels using controllable flaps. The effect of static transom flap deflection on the running attitude and motion stability was investigated by developing a Linear Quadratic Regulator (LQR) feedback controller. Fast sea transportation usually encounters some problems in seakeeping. The vertical motions on these ships have negative effects such as sea sickness, structural damage and navigation risks. To counteract these Esteban et al.,[11] fitted a pair of transom flaps and a T-foil near the bow. The frequency-domain models are used to study the effects and found a good comparison with experimental work done in CEHIPAR with reduced sea sickness effect and wave excitation.

Sebastiani et al.,[27] worked on a 2D formulation based on momentum theory for the prediction of pitch, heave, and roll motions for a planing hull in regular and irregular waves. Encouraging results were presented with some shortcomings for which further investigation and analysis was needed. In general, the horizontal, transverse and vertical motions are seen in planing hulls at high speeds. These dynamic instabilities like porpoising, which is an oscillatory motion in the vertical plane in planing hulls are studied by Xi et al.,[37]. Lee et al., [22] carried out numerical studies on KCS vessel to accurately find the resistance and motions in regular waves. Their studies found good agreement with experimental data. A reduction in instability was observed in the investigation done on planing hulls with appendages like flaps and wedges. It was established that the appendages can produce additional lift due to the pressure created and allow the vessel to reach a dynamic equilibrium whereas the vessel with no appendages would not experience it. Many researchers have been working to improve the stability of the high-speed craft in calm water and waves. In Deyzen [35] used a proactive control of thrust force to control instability in high-speed vessels. Recent developments in computational science paved the path to more detailed representation of body motions inside fluids. Using the benefits that computational science brings, the flow is visualized to explain some physics relevant to the planing hull in waves. Sun et al.,[29] carried out numerical study on the performance of planing vessel in waves using $2 \mathrm{D}+\mathrm{t}$ theory to solve the unsteady problem in waves. Fully nonlinear time-dependent 2D problems are derived and solved by using the Boundary Element Method. The heave and pitch motions induced by the waves are calculated using the force and moment integrated from the pressures obtained in the 2D problems. Faltinsen et al.,[16] used the 2D+t nonlinear method to study the proposing and wave-induced motions and accelerations of planing vessel in a head sea. Slamming on wet deck was done as separate analysis where they included the effect of local hydroelasticity. Pigazzini et al., [25] conducted experiments on warped hard chine hulls for assessing the vertical motions and accelerations in regular waves. They found that the peak motion and acceleration response occur at higher wavelengths. The resistance and seakeeping performance of high-speed crafts has always been a challenge in calm water and waves which changes significantly depending on the hull form. Ghadimi et al.,[17] developed a mathematical model for the prediction of the 6-DOF motion of planing crafts in regular waves. Kohansal et al.,[21] developed numerical algorithm based on BEM to predict the hydrodynamic characteristics of various planing hull forms. Three deep V-planing models with different bow shapes and L/B ratios are considered by Kim et al.,[9] to study the effect of motions and the seakeeping performance is improved with large L/B ratio. The heave and pitch motions are calculated directly from URANS and DFBI equations where the detailed information was given by Carrica et al., [6], Carricaet al., [5], Cakici et al., [8], Ozdemir et al., [24], Tezdogan et al., [33], Tezdogan et al., [34]. Amin et al., [2] studied on the hydrodynamic coefficients on a catamaran with and without hydrofoil using RANS method. Their studies reported that the coefficients are frequency independent at high frequencies. 
The published results on the interceptor and its application on high-speed crafts in wave condition are sparse. Hence, exploring the effect of interceptor on planing hull is specifically aimed at predicting the behavior of the vessel in regular head waves. The present study aims at improving the impact of interceptors on the motions by reviewing the published literature sources, examining its impact on sea keeping quality through numerical study. The effects of interceptor on running attitude and vertical plane motions are investigated. During pitch and heave, there is an impact on the bottom structure of a ship onto the sea surface when the bow rises up from the water and subsequently impacts on it. When designing ships, pitch and heave motions are taken into consideration which induce extremely high loads to ship structures.

In this study, the sea keeping performance of planing hull with and without interceptor is numerically verified by RANS solver using STAR CCM+ and conducting numerical simulations. Numerical studies on the vessel using dynamic mesh are validated with experimental results in calm water for different Froude numbers. The focus of the present study is to numerically analyze the effect of interceptor on the sea keeping behavior advancing in regular head waves for a high-speed planing hull. Section 2 presents methodology used for carrying out the numerical simulations in the RANS based CFD solver and Section 3 reports the validation of numerical results with experimental data for bare hull in calm water. Section 4 presents and discusses the results followed by Section 5 on the summary and conclusions drawn from the present study.

\section{Numerical modelling}

\subsection{Vessel particulars}

The principal particulars of high-speed planing hull considered for study is shown in Table 1 .

Table 1: Principal particulars of the craft (scale: 1:25)

\begin{tabular}{|l|l|l|}
\hline Particulars & Prototype & Model \\
\hline Length overall, $L,[\mathrm{~m}]$ & 20.0 & 0.82 \\
\hline Maximum Breadth, $B,[\mathrm{~m}]$ & 5.30 & 0.212 \\
\hline Draft, $T,[\mathrm{~m}]$ & 1.062 & 0.046 \\
\hline Depth, $D,[\mathrm{~m}]$ & 1.03 & 0.0412 \\
\hline Displacement, $4,[\mathrm{~kg}]$ & 46000 & 2.94 \\
\hline LCG from the transom, $[\mathrm{m}]$ & 6.5 & 0.26 \\
\hline Design speed, $V$ & $25 \mathrm{knots}$ & $2.57 \mathrm{~m} / \mathrm{s}$ \\
\hline Block coefficient, $C_{b}$ & \multicolumn{2}{|c|}{0.41} \\
\hline Deadrise angle, $\beta,[\mathrm{deg}]$ & \multicolumn{2}{|c|}{20} \\
\hline Wavelength, $\lambda,[\mathrm{m}]$ & $\mathrm{L}, 2 \mathrm{~L}, 3 \mathrm{~L}, 4 \mathrm{~L}$ \\
\hline
\end{tabular}

Growth in computational power made possible in solving the RANS equations and apply them in the prediction of performance of the vessel. These equations take into account the nonlinearities associated with free surface flows and viscous effects of the fluid. The numerical method used is finite volume method in which the flow is assumed to be governed 
by RANS equations. The numerical simulations in this study cover the flow conditions of beam Froude number $\left(F r_{B}\right)$ between 1.57 and 2.28 and wavelengths ranging from $\lambda=0.8$ to 3.2. In this operating range, the effect of exciting forces due to incoming wave is expected. A numerical study was undertaken to analyze the heave and pitch responses for different wave lengths also. The spatial fluid domain is discretized into finite number of control volumes. Finite volume CFD software STAR CCM+ is used in this study for the investigation. Numerical modeling is performed to simulate the high-speed vessel with consequent dynamic changes in trim, sinkage and motions.

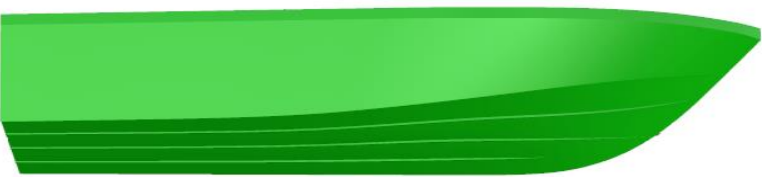

(a)

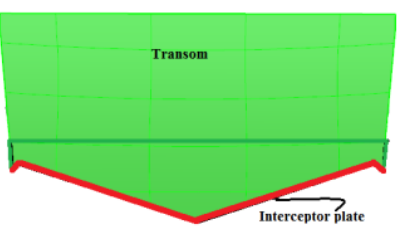

(b)

Fig 1: CAD model of planing hull showing (a) profile view (b) transom with interceptor

The determination of resistance and trim angle of a planing craft for different speeds involves simulation of waves that occur on the free surface. In Fig 1(a) represents the profile view of the CAD model, Fig 1(b) showing the transom with interceptor. The vessel is towed through calm water to get the resistance and trim and through regular head waves to get motions. The steepness ratio, $H / \lambda$ (wave height to wavelength) is $1 / 50$ which is maintained constant as per ITTC 7.5-02-07-02.1[20]. The motions are studied numerically using CFD software STAR $\mathrm{CCM}+$ using the overset mesh. The RANS equations are used to study the flow around the ship in calm water and waves. To solve these equations a set of initial and boundary conditions are given as shown in Table 2.

\subsection{Computational domain and boundary conditions}

Tests are conducted in numerical wave tank using RANSE based CFD software. A large rectangular domain is created in order to avoid effects from the domain boundaries. The vessel is enclosed by 3D rectangular computational domain over which the flow is solved. In Fig 2, the computational domain is illustrated, and its dimensions are expressed in terms of overall hull length, L.

To capture the flow phenomenon the domain boundaries within which the modeled computational grid is extended to $L$ from bow, $4 L$ from the aft, $2 L$ from the keel and $L$ from the side of the hull where $L$ is the length of the ship, as shown in Fig 2 . These dimensions agree well with the minimum recommendations of ITTC [19]. 


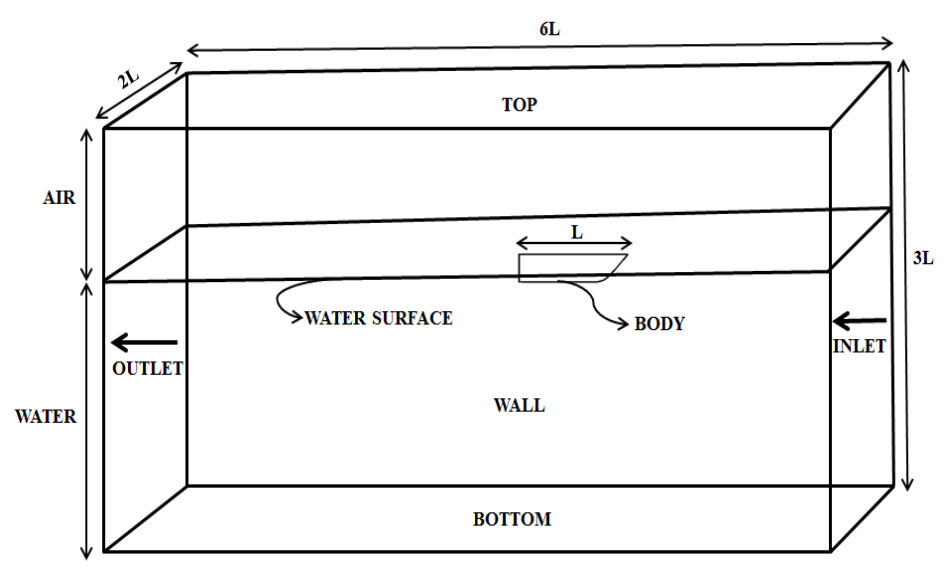

Fig 2: Computational domain with boundary conditions

The top, side and bottom of the domain were prescribed with slip boundary conditions, and hull was set to wall with no-slip. Inlet boundary is taken as velocity inlet. The outlet, located behind the hull, was set to pressure outlet. This boundary is placed far enough to ensure that the flow is fully developed so that no fluctuations or reflections occur in the flow direction. The inlet boundary conditions are used to initialize the flow field in the domain. Symmetry condition is used because of the symmetry in the geometry, which reduces the computational effort. The normal velocity and normal gradients of all variables are zero at symmetry plane. Table 2 shows the boundary conditions taken for the simulation of motions in regular head waves.

Table 2: Boundary conditions of model craft in head wave simulation

\begin{tabular}{|l|l|}
\hline Surface & Boundary condition \\
\hline $\begin{array}{l}\text { Inlet, bottom, side, } \\
\text { top }\end{array}$ & Velocity inlet \\
\hline Outlet & Pressure outlet \\
\hline Symmetry & Symmetry plane \\
\hline Body & Wall (No slip) \\
\hline
\end{tabular}

\subsection{Solver parameters}

The flow equations are solved sequentially in segregated solver where the pressure and velocity change with time. The procedure adopted in this study for coupling the pressure and velocity is SIMPLE (Semi-Implicit Method for Pressure Linked Equations). A summary of the solver settings is given in Table 3. The free surface modeling technique, Volume of Fluid (VOF) method is used to simulate regular head waves in the current study. This model provides field functions that can be used to initialize the VOF wave formulation. The number of inner iterations taken is 10 per time step. The realizable $k-\varepsilon$ turbulence model is used to capture free surface flow. The height of cells on walls is determined to contain the y+ values. Near wall y+ is kept between 30 and 300. Prism layers are adopted near the wall for accurate description of boundary layer. The total cell count for the simulation in waves is about $4.55 \times 10^{6}$. The Dynamic Fluid Body Interaction (DFBI) is used to simulate the motion of the body according to the forces acting on it induced by the flow. The linear interpolation scheme 
is used to create the interface between background mesh and overset mesh. The ship is allowed to move with two degrees of freedom to account for sinkage and trim.

Table 3: Solver parameters used in head wave simulation

\begin{tabular}{|l|l|}
\hline Parameter & Settings \\
\hline Solver & 3D, Unsteady, Implicit \\
\hline Turbulence model & Realizable k- $\varepsilon$ \\
\hline Pressure-velocity coupling & SIMPLE \\
\hline Multiphase model & Volume of Fluid(VOF) \\
\hline Wall treatment & Two layers all wall y+ treatment \\
\hline Time discretization & First order upwind \\
\hline Number of inner iterations & 10 \\
\hline Overset interpolation scheme & Linear \\
\hline Motion solver & Dynamic Fluid Body Interaction (DFBI) \\
\hline Degree of Freedom & Heave and Pitch \\
\hline
\end{tabular}

\subsection{Grid independent study}

To verify the mesh independency of the solution, the coarser, medium and finer mesh are generated. The resulting coarser, fine and finest grid sizes are $1.34,1.92$ and $2.81 \times 10^{6}$ respectively. The grid independent study was done for the resistance and trim in calm water to fix the base grid. Grid independent study is carried out to obtain reliable values based on grid refinement ratio of $\sqrt{2}$, where the minimum cell size near the hull surface is multiplied by $\sqrt{2}$ to get the next grid. Table 4 shows the grid independency at $F r_{B}=1.78$ in calm water. From the grid independent study, grid no.2 is selected for the simulation process.

Table 4: Grid independency study at $\mathrm{Fr}_{\mathrm{B}}=1.78$

\begin{tabular}{|c|c|c|c|c|c|}
\hline Grid no. & $\begin{array}{c}\text { Cell count } \\
\text { (million) }\end{array}$ & $\begin{array}{c}R_{t} / \mathrm{disp} . \\
(\mathrm{N} / \mathrm{kg})\end{array}$ & $\%$ error & $\begin{array}{c}\text { Trim } \\
(\mathrm{deg})\end{array}$ & \% error \\
\hline 1 & 1.34 & 1.45 & 6.45 & 6.54 & 4.1 \\
\hline 2 & 1.92 & 1.51 & 2.58 & 6.68 & 2.05 \\
\hline 3 & 2.81 & 1.53 & - & 6.82 & - \\
\hline Experiment & - & 1.49 & & 6.65 & \\
\hline
\end{tabular}

\subsection{Mesh generation}

Head waves are simulated by generating the grid with prismatic near-wall layers using CFD tool. The computational domain includes overset mesh option which has two different regions 
i.e; overset mesh and background mesh (Bertorello et al., [3]). The background mesh is static where far field boundary conditions are imposed and overset mesh is dynamic (moves along with the hull) over a static background mesh of the whole domain. Fig 3 shows the mesh generated in the domain.

$$
\Delta t=0.005 x \frac{L_{K}}{V}
$$

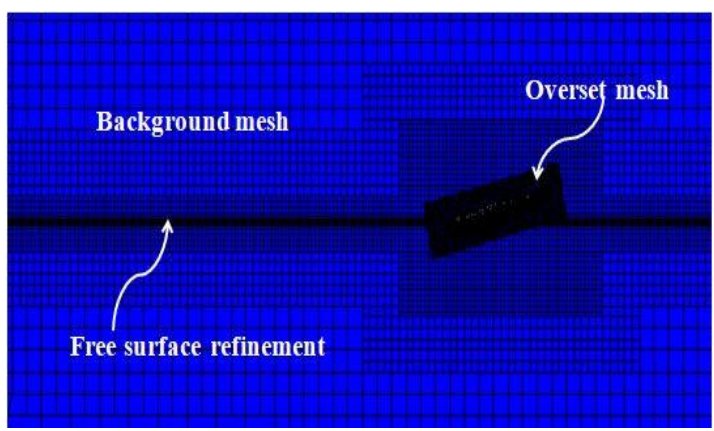

Fig 3: Mesh generated in the computational domain.

The time-step $(\Delta \mathrm{t})$ used in the simulations, function of hull speed $(V)$ and wetted keel length $\left(L_{K}\right)$, is determined from equation 1, according to ITTC [19]. The simulation of ship's motion in calm water is transformed to flat wave and in waves it is adopted to the first order waves. Around 80 grid points per wave length are used to capture the wave in longitudinal direction and 40 cells per wave height, in vertical direction to resolve free surface (CD ADAPCO, [7]). In this simulation, 15 layers were allocated to build the prism layer for simulating waves. To replicate the dynamic tests, overset meshing option is used for imposing prescribed motion to the hull.

\section{Validation}

\subsection{Resistance and trim in calm water}

Experiments were done on the planing hull model with and without interceptor in calm water at different speeds. The numerical results obtained using RANS method is compared with experimental results. Both the experimental and numerical results are found to agree well with each other.

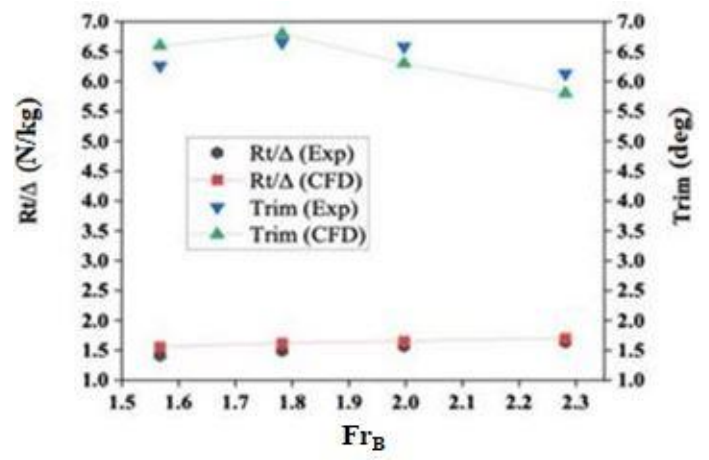

Fig 4: Comparison of experimental and CFD results for resistance and trim for barehull at different Froude beam numbers. 
Fig 4 shows the comparison results of CFD with experiments for resistance and trim without interceptor for various speeds. It is observed that the resistance of the vessel obtained from experiments for hull without interceptor is quite closer to the CFD results.

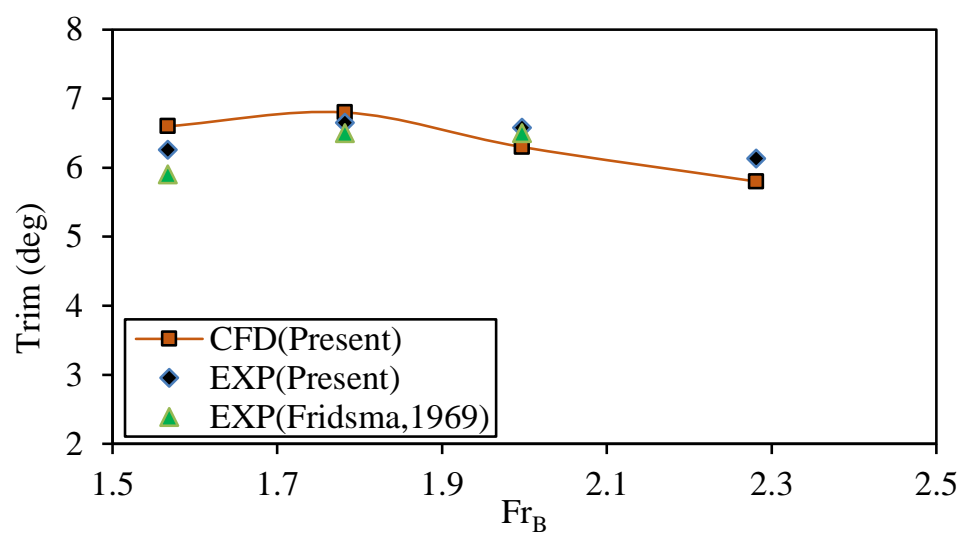

Fig 5: Comparison of experimental and CFD results of trim for bare hull at different beam Froude number in calm water

Fig 5 depicts the trim for different beam Froude numbers compared with experiments done on present planing hull model and experimental work done by Fridsma [15] and also CFD results in calm water. It is observed that the trim is decreasing with increase in speed. Both the experimental results are following the same trend of decrease in trim with an increase in speed and have good correspondence.

\section{Results and discussion}

A high-speed planing vessel model with a design speed of $F r_{B}=1.78$ is considered for the study in regular head waves. The current numerical solution is validated with the resistance of the vessel in calm water obtained using STAR CCM+ by comparing against experimental data for the hull with and without interceptor at different beam Froude numbers. The beam Froude number is given by $F_{r B}=\frac{V}{\sqrt{g B}}$ where $V$ is the speed of the vessel, $\mathrm{g}$ is the acceleration due to gravity and $B$ is beam of the vessel.

\subsection{Resistance}

The simulation study in head wave condition show that the resistance for bare hull is higher when compared to hull with interceptor. With increase in wavelength the resistance is also increasing. Table 5 and Fig 6 display the resistance for different wavelengths on barehull and hull with interceptor. However, the resistance of the hull is more in wave condition when compared to the calm water condition.

Table 5: Resistance of barehull and hull with interceptor for different wavelengths at $\mathrm{Fr}_{\mathrm{B}}=1.78$

\begin{tabular}{|c|c|c|}
\hline$\lambda(m)$ & $\begin{array}{l}\text { Resistance } \\
\text { barehull(N/kg) }\end{array}$ & $\begin{array}{l}\text { Resistance interceptor } \\
(\mathrm{N} / \mathrm{kg})\end{array}$ \\
\hline $\mathrm{L}$ & 2.24 & 1.91 \\
\hline $2 \mathrm{~L}$ & 2.30 & 1.95 \\
\hline $3 \mathrm{~L}$ & 2.31 & 2.09 \\
\hline
\end{tabular}




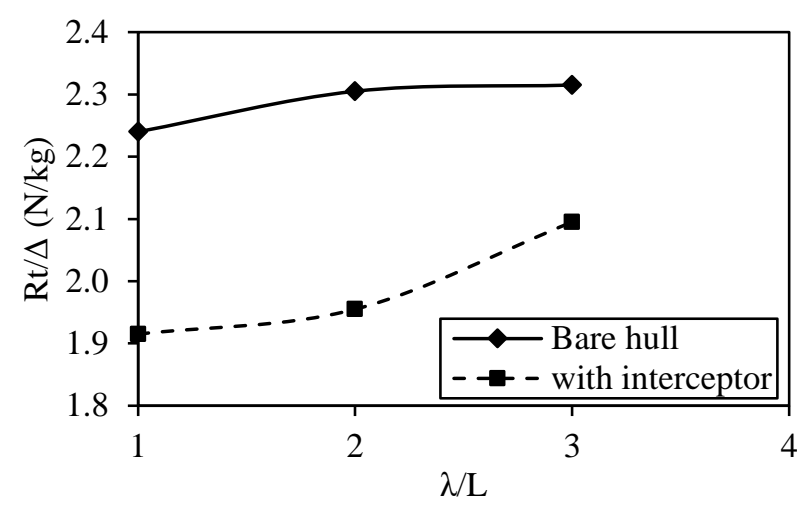

Fig 6: Comparison of resistance for barehull and hull with interceptor of different wavelengths at $F r_{B}=1.78$.

4.2 Natural and encounter frequency of planing hull

The equations of heave and pitch motions are derived from the solution of homogenous system where there are no forces. They are explained in analogy to mass-spring damper system with forced motions. These equations are valid for monohulls where in the cases of small and uncoupled motions are assumed. The equations used for calculating the natural heave and pitch frequencies $\omega_{3}$ and $\omega_{5}$ are given as follows:

$$
\begin{gathered}
\omega_{3}=\sqrt{\frac{C_{33}}{m+A_{33}}} \\
\omega_{5}=\sqrt{\frac{C_{55}}{I_{55}+A_{55}}}
\end{gathered}
$$

where $C_{33}$ and $C_{55}$ are heave force $\left(\rho g A_{w}\right)$ and pitch moment $\left(\rho g I_{L}\right)$ and $A_{33}, A_{55}$ are heave added mass and pitch added inertia, $\mathrm{I}_{55}$ is the mass moment of inertia about $\mathrm{y}$-axis and $\mathrm{m}$ is the mass of vessel. The equations (2) and (3) are simplified by assuming $A_{55} \approx I_{55}$ and $A_{33} \approx m$. Therefore the natural frequency $f_{n}=\omega / 2 \pi$ derived for motions of ship are given as follows.

$$
\begin{gathered}
f_{n 3}=\sqrt{\frac{g C_{W P}}{8 \pi^{2} C_{B} T}} \\
f_{n 5}=\sqrt{\frac{g B^{3} C_{I L}}{96 \pi^{2} I_{55} L_{p p}^{4}}}
\end{gathered}
$$

In the above equations $C_{w p}$ is the water-plane coefficient given as $A_{W} / B L_{P P}, A_{W}$ is the waterplane area of the hull, $B$ is the beam and $L_{P P}$ is the length between perpendiculars. $C_{I L}=12 I_{L} / B^{3} L_{P P}$ is the coefficient of inertia of water-plane area about y-axis where $\mathrm{I}_{\mathrm{L}}$ is moment of inertia of the water-plane. Finally the non-dimensional mass moment of inertia is given by $\hat{I}_{55}=I_{55} / \rho L_{P P}^{5}$ about y-axis. The natural heave frequency is $1.35 \mathrm{~Hz}$ and pitch frequency is 1.33 $\mathrm{Hz}$.

Frequency of the wave excitation force on the vessel and its consequent motions are not only dependent upon the wave frequency and direction of wave but also on the speed and heading of the vessel, which determines the wave frequency in relation to the moving vessel, termed as encounter frequency $\left(\omega_{e}\right)$. The encounter frequency is given by $\omega_{e}=\omega+k V \cos \mu$, where the wave number $k=\omega^{2} / g, \mu$ is the direction of wave propagation about the vessel longitudinal 
axis, $\omega$ is the wave frequency in $\mathrm{rad} / \mathrm{sec}, V$ is the speed of vessel in $\mathrm{m} / \mathrm{s}, \mathrm{g}$ is acceleration due to gravity in $\mathrm{m} / \mathrm{s}^{2}$. The wave frequency $(\omega)$ is given by $V / \lambda$ where $V$ is speed of vessel in $\mathrm{m} / \mathrm{s}$ and $\lambda$ is wavelength in $\mathrm{m}$. In general the encounter frequency $\left(\omega_{e}\right)$ is greater than wave frequency $(\omega)$ in head waves. Table 6 shows the wave frequency $(\omega)$, corresponding encounter frequency $\left(\omega_{e}\right)$, heave and pitch RAOs from simulations for different wavelengths at $F r_{B}=1.78$ while the vessel heads into the wave ( $\left.\mu=180 \mathrm{deg}\right)$.

Table 6: Wave frequency and encounter frequency for different wavelengths at $F r_{B}=1.78$.

\begin{tabular}{|l|c|c|c|c|}
\hline$\lambda(m)$ & $\mathrm{L}$ & $2 \mathrm{~L}$ & $3 \mathrm{~L}$ & $4 \mathrm{~L}$ \\
\hline$\omega(\mathrm{rad} / \mathrm{sec})$ & 3.13 & 1.57 & 1.05 & 0.78 \\
\hline$\omega_{e}(\mathrm{rad} / \mathrm{sec})$ & 5.69 & 2.21 & 1.33 & 0.94 \\
\hline
\end{tabular}

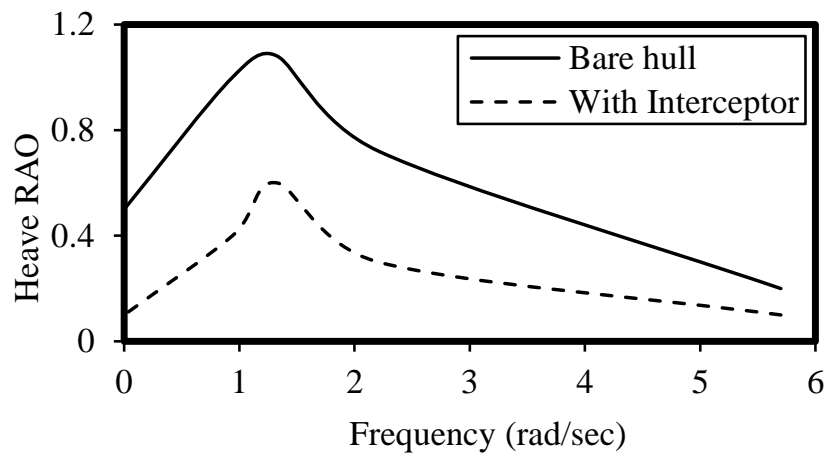

(a)

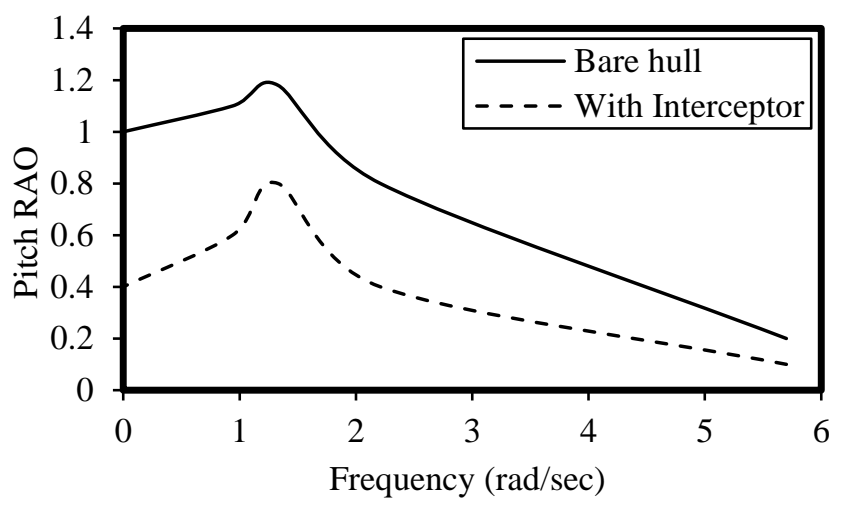

(b)

Fig 7: Heave and pitch RAO at $F r_{B}=1.78$ for different frequencies.

In RAO heave movements at $F r_{B}=1.78$ can be seen (Fig. 7a) on the curve that bare hull critical peak value of heave RAO is $1.08 \mathrm{~m}$ with a frequency of $1.05 \mathrm{rad} / \mathrm{sec}$ and hull with interceptor having critical peak value of heave RAO is $0.6 \mathrm{~m}$ with a frequency of $1.05 \mathrm{rad} / \mathrm{sec}$. In RAO pitch movements at $F r_{B}=1.78$ can be seen (Fig. 7 b) on the curve that bare hull critical peak value of pitch RAO is $1.05 \mathrm{~m}$ with a frequency of $1.18 \mathrm{rad} / \mathrm{sec}$ and hull with interceptor having critical peak value of pitch RAO is $0.8 \mathrm{~m}$ with a frequency of $1.05 \mathrm{rad} / \mathrm{sec}$. 


\subsection{Heave motions for the hull with and without interceptor}

Prediction of vessel performance in calm water and wave condition is one of the imperative concerns and sea keeping performance is one of the most important aspects. The heave motion of planing vessel for the hull with and without interceptor is studied numerically in head waves for different wavelengths at $F r_{B}=1.78$. Since the waves have to build the motions, they are irregular in the first few seconds of the simulation and become regular after a few seconds. The heave and pitch motions are observed for the model with the increasing speed of different wavelengths. The comparison of heave RAO (Response Amplitude Operator) for the planing hull with and without interceptor is shown in Fig 8 for different wavelengths at $F_{B}=1.78$. It is observed that heave RAO is reduced using interceptor when compared to the hull without interceptor.

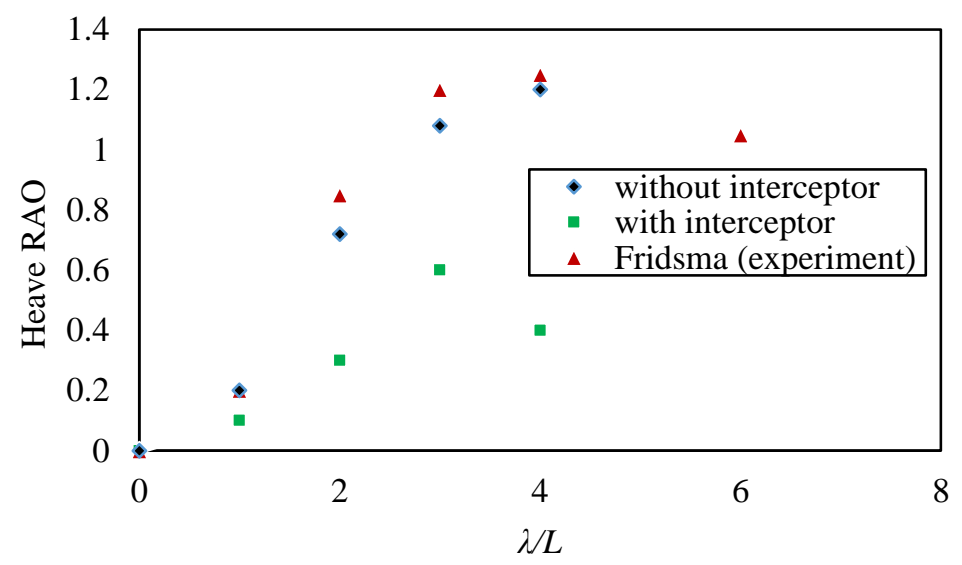

Fig 8: Comparison of heave RAO at $F r_{B}=1.78$ on the hull with and without interceptor and Fridsma experiments in head waves (bare hull).

Fig 8 illustrates the heave RAO at $F r_{B}=1.78$ for different wavelengths with and without interceptor and compared against Fridsma [15] experimental data for hull without interceptor. It is observed that there is a reduction in the heave $\mathrm{RAO},(\mathrm{h} / H$ where $\mathrm{h}$ is heave amplitude and $H$ is wave height) with the interceptor when compared to the hull without interceptor. There is 14-34 percentage of decrease in the heave RAO when compared to the hull without interceptor at $F r_{B}=1.78$ for different wavelengths.

\subsection{Comparison of heave motions for the hull with and without interceptor}

The motions of planing vessel for the hull with and without interceptor are studied numerically in head waves for different wavelengths at $F r_{B}=1.78$. The heave motions are observed for the model. The effects of heave motions for different wavelengths are studied for the hull with and without interceptor. 


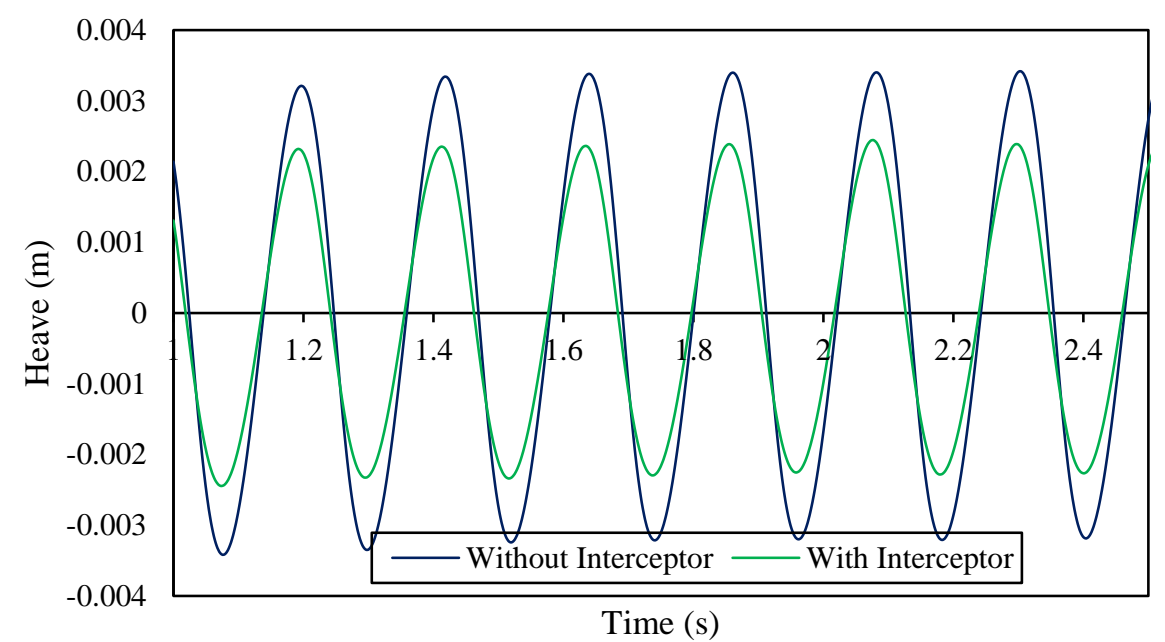

Fig 9: Heave of craft at $F_{B}=1.78$ on the hull with and without interceptor for $\lambda=L$

Fig 9 shows the time history curve of heave for a period of time at $F r_{B}=1.78$ on the hull with and without interceptor for $\lambda=L$. The amplitude value of motion for the hull without interceptor is higher when compared to the hull with interceptor. This reduction in heave motion will help in having a good sea keeping behaviour.

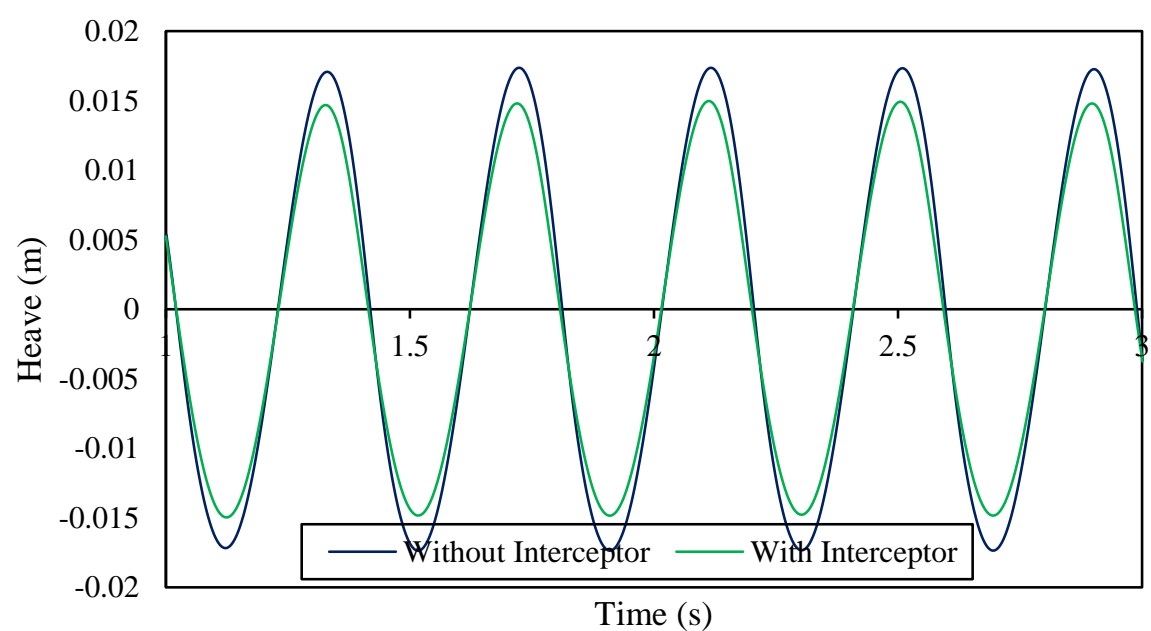

Fig 10: Heave of craft $F r_{B}=1.78$ on the hull with and without interceptor for $\lambda=2 L$

Fig 10 shows the time history curve of heave motion of the craft at $F r_{B}=1.78$ for the hull with and without interceptor for $\lambda=2 L$. The amplitude of motion for the hull without interceptor is higher when compared to the hull with interceptor. The amplitude of motion is decreasing with an increase in wavelength. The number of oscillations are more for $\lambda=L$ when compared to $\lambda=2 L$. 


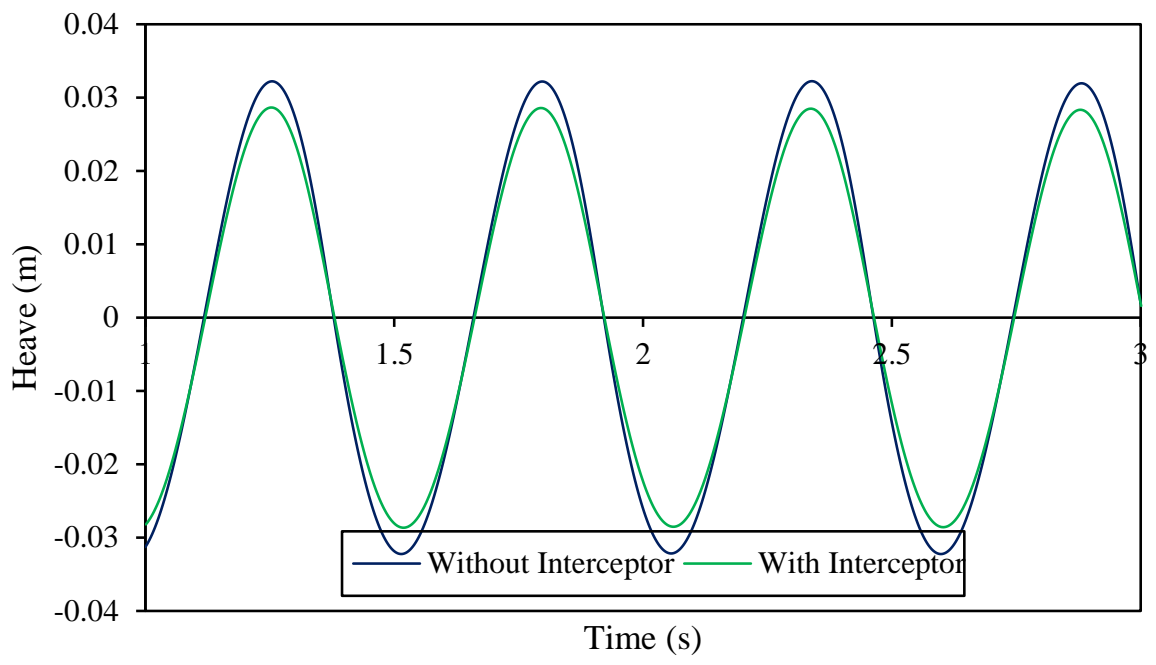

Fig 11: Heave of craft at $F r_{B}=1.78$ on the hull with and without interceptor for $\lambda=3 L$

In Fig 11 the time history curve of heave of the hull with and without interceptor for a wavelength of $\lambda=3 L$ at $F r_{B}=1.78$ is shown. It is observed that the heave of the hull with interceptor is less when compared to the hull without interceptor. Moreover, the amplitude for the hull without interceptor is high compared to the hull with interceptor.

The variation in heave amplitude at different speeds for the wavelength $\lambda=L$ on the hull without interceptor is observed. It shows that with increase in speed the motions on the vessel are increasing. Here concentration is made only on the design speed of $F r_{B}=1.78$ on the craft. There is a reduction in the oscillation of motion of the craft at shorter wavelengths with an increase in speed. It is observed that as the speed is increasing the amplitude of motions on the vessel is increasing and the heave motions are higher with the increase in speed for the wavelength of $\lambda=2 L$. The number of oscillations for $\lambda=2 L$ is less compared to $\lambda=L$. Here heave is in z-direction and bow moving downwards. Maximum motions in all cases occur at wavelengths equal to two or three times hull length. This is in accordance with the Fridsma [15] experimental study. It is observed that there is 16-18 percentage reduction in heave motions at the design speed for different wavelengths.

\subsection{Pitch motions for the hull with and without interceptor}

The pitch motions of planing vessel for the hull with and without interceptor are presented numerically in head waves for different wavelengths at different beam Froude numbers. Since the waves have to build the motions first they are irregular in the first few seconds of the simulation and become regular after a few seconds.

Here pitch is about y-axis which causes the bow up. Pitch RAO is given by pitch amplitude /slope. It is observed that with increasing wavelength the pitch amplitude is also increasing. The numbers of oscillations with an increase in wavelength are less. 


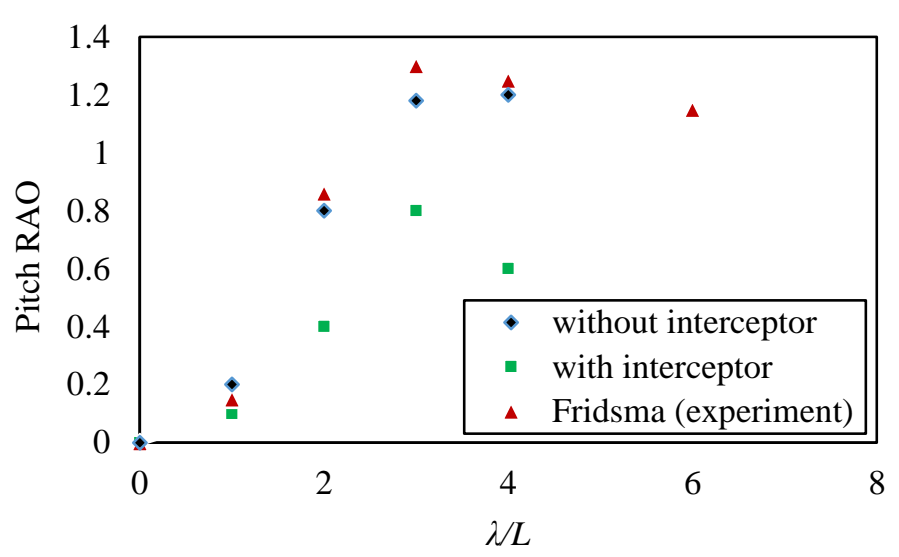

Fig 12: Pitch RAO of craft at $\mathrm{Fr}_{B}=1.78$ on the hull with and without interceptor for different wavelengths

Fig 12 shows the pitch RAO for hull with interceptor at wavelengths of $L, 2 L, 3 L$ and $4 L$ with and without interceptor. It is observed that the pitch RAO is less, with the interceptor when compared to the hull without interceptor. The pitch RAO is higher for wavelengths from $L$ to $3 L$ and starts decreasing with increase in wavelength. Table 7 shows the heave and pitch RAO for different wavelengths for the bare hull and hull with interceptor.

Table 7: Heave and Pitch RAO for different wavelengths

\begin{tabular}{|c|l|l|l|l|}
\hline$\lambda(\mathrm{m})$ & \multicolumn{1}{|c|}{$\mathrm{L}$} & $2 \mathrm{~L}$ & $3 \mathrm{~L}$ & $4 \mathrm{~L}$ \\
\hline $\begin{array}{c}\text { Heave RAO (Bare } \\
\text { hull) }\end{array}$ & 0.2 & 0.72 & 1.08 & 1.0 \\
\hline $\begin{array}{c}\text { Heave RAO } \\
\text { (Interceptor) }\end{array}$ & 0.1 & 0.3 & 0.6 & 0.4 \\
\hline $\begin{array}{c}\text { Pitch RAO (Bare } \\
\text { hull) }\end{array}$ & 0.2 & 0.8 & 1.18 & 1.1 \\
\hline $\begin{array}{c}\text { Pitch RAO } \\
\text { (Interceptor) }\end{array}$ & 0.1 & 0.4 & 0.8 & 0.6 \\
\hline
\end{tabular}

\subsection{Comparison of Pitch motions for the hull with and without interceptor}

The motions of planing vessel for the hull with and without interceptor studied numerically in head waves for different wavelengths at $F r_{B}=1.78$ are presented. The pitch motions are observed for the model of different wavelengths. The effects of pitch motions for different wavelengths are studied for the hull with and without interceptor. 


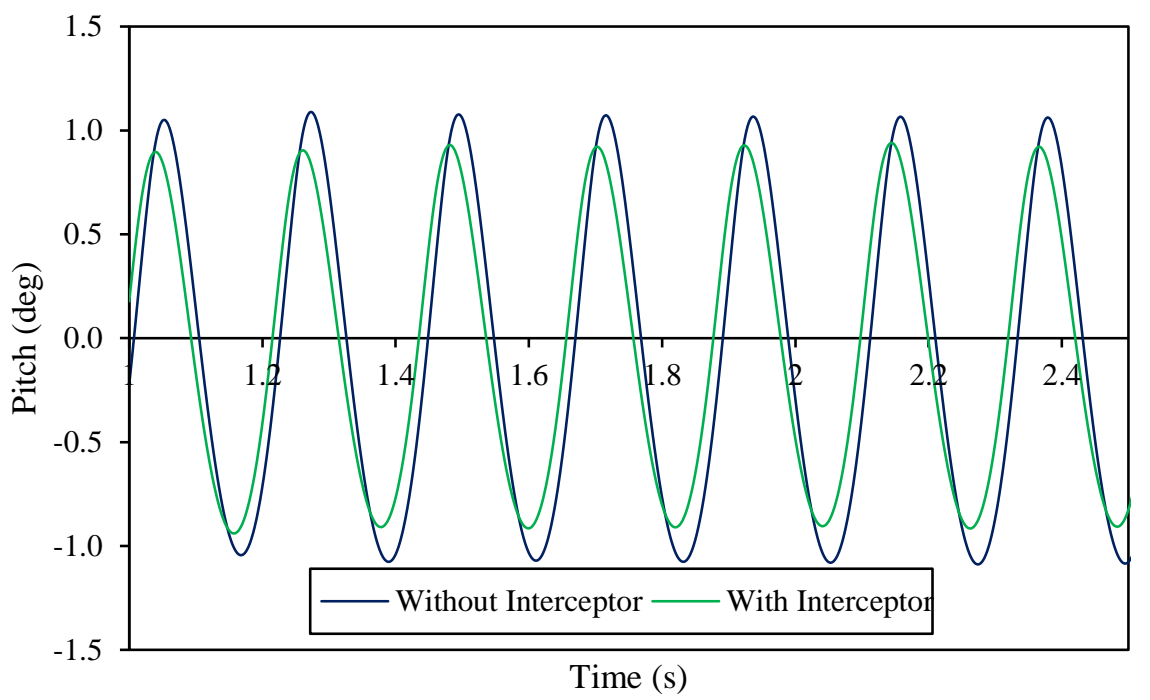

Fig 13: Pitch of craft at $\mathrm{Fr}_{\mathrm{B}}=1.78$ on the hull with and without interceptor for $\lambda=L$

Fig 13 shows the time history curve of pitch of the craft for the hull with and without interceptor at $F r_{B}=1.78$ and $\lambda=L$. The amplitude of motion for the hull without interceptor is higher when compared to the hull with interceptor. The pitch motions are less for the hull with interceptor when compared to the hull without interceptor.

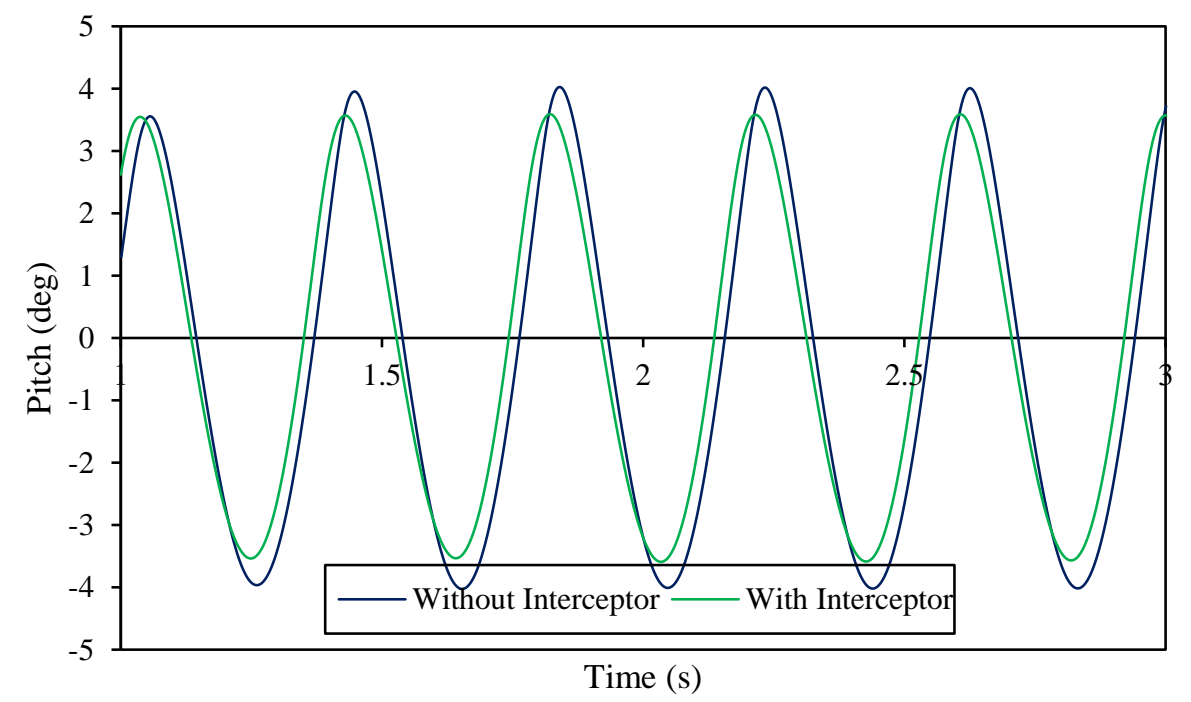

Fig 14: Pitch of craft at $\mathrm{Fr}_{B}=1.78$ on the hull with and without interceptor for $\lambda=2 L$.

Fig 14 shows the time history curve of pitch motion of the craft for the hull with and without interceptor at $F r_{B}=1.78$ and $\lambda=2 L$. The amplitude of motion for the hull without interceptor is higher when compared to the hull with interceptor. The pitch motions are less for the hull with interceptor when compared to the hull without interceptor. The number of oscillations are decreasing with increase in wavelength.

The heave and pitch motions are observed for the model with the increasing speed for different wavelengths. The pitch amplitude for the hull with and without interceptor at different speeds for a wavelength of $\lambda=2 L$. It depicts that the pitch motions are higher at low 
speeds but the amplitude is less with increase in speed. The pitch amplitude for the planing hull with and without interceptor for the wavelength of $\lambda=2 L$ is observed that with the increase in speed the amplitude of pitch motions are less. The oscillations for wavelength $\lambda=2 L$ are less when compared to the wavelength of $\lambda=L$.

\subsection{Free surface wave pattern}

The free surface flow is important to know the flow modelling around the floating body. The free surface wave pattern for the bare hull and hull with interceptor for different wavelengths at $F r_{B}=1.78$ are shown in Fig 15 .

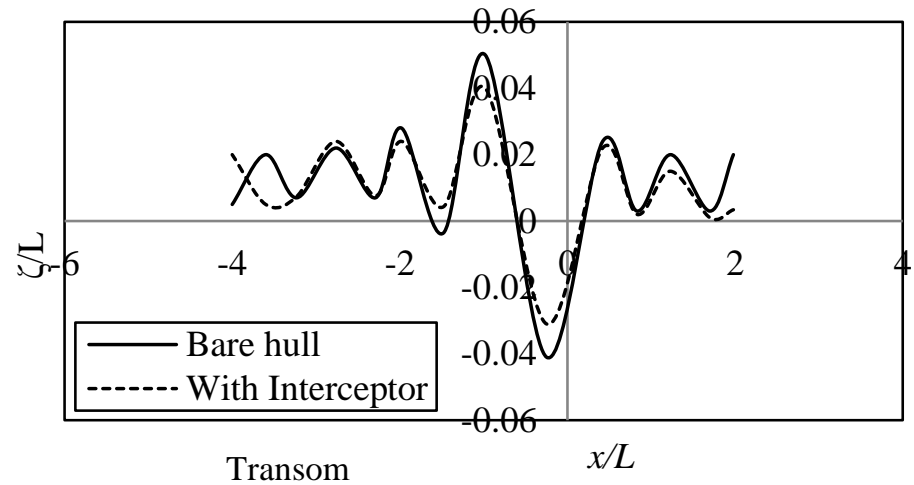

(a)

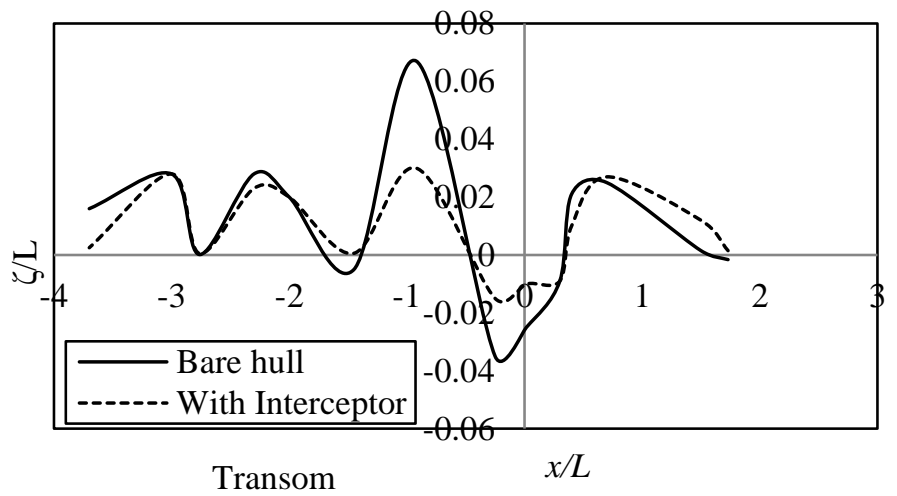

(b)

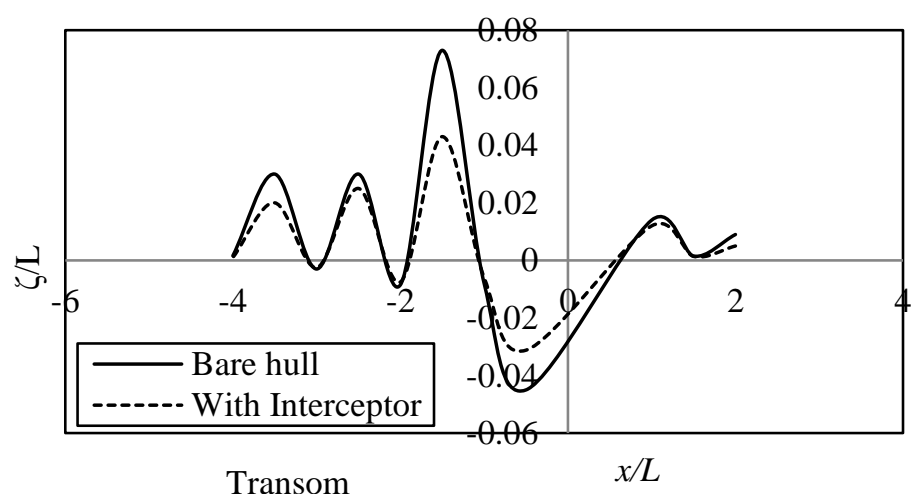

(c)

Fig 15: Free surface wave pattern for (a) $\lambda=\mathrm{L}$ (b) $\lambda=2 \mathrm{~L}$ (c) $\lambda=3 \mathrm{~L}$ at $F r_{B}=1.78$. 
Fig 15 shows the wave profile obtained for different wavelengths at $F r_{B}=1.78$ for the bare hull and with interceptor. The profile of wave is taken as intersection of wave pattern with cutting plane $-4 \leq x / L \leq 0.82$. The hull is placed with transom at $x / L=0$. Fig 15 a shows the wave elevation for $\lambda=L$, Fig $15 \mathrm{~b}$ shows the wave elevation for $\lambda=2 L$ and Fig $15 \mathrm{c}$ shows the wave elevation for $\lambda=3 L$. It is observed that the wave elevation for $\lambda=L$ and $3 L$ is more where resistance is also high when compared to $2 L$. When interceptor is fitted it is observed that the resistance is reduced for all cases.

\section{Summary and Conclusion}

The planing hull model was investigated numerically for the seakeeping performance with and without interceptor in waves. Experimental tests were performed in the Towing tank, IIT Madras, India, in calm water condition to study the effect of interceptor. The numerical study is also carried out for the same vessel using RANSE commercial software for the hull with and without interceptor in calm water. The resistance and trim values are recorded from experiments in calm water. The numerical results are validated with experimental results where good agreement was found. Further, the study on heave and pitch motions are captured numerically in waves for the same planing hull with and without interceptor. The resistance is decreasing with interceptor when compared to the hull without interceptor for different wavelengths at various beam Froude numbers. In the presence of waves, low trims reduce accelerations. In this sense, the bare hull with CG aft provides a not very significant reference. The analysis on comparing the fairings with different positions of CG and highlighting the intrinsic effectiveness of interceptor by placing the CG of bare hull in the position with which the trim of this at $F r_{B}=1.78$ is equal to that of interceptor is considered as future work.

- The amplitude of heave motions is less for the hull with interceptor in comparison to the hull without interceptor.

- There is a reduction of 16-18 percentage in heave motion for the hull with interceptor of different wavelengths at $\mathrm{Fr}_{B}=1.78$.

- The amplitude of heave and pitch motions is increasing with the increase in speed for different wavelengths.

- Moreover, the number of oscillations is less with increase in wavelength at different Froude numbers.

- The simulated results show that the interceptors can be used to minimize pitch motion as well as the heave motion on the craft.

- However, using interceptors both the pitch and heave motions can be effectively reduced compared to the hull without interceptor in calm water and regular head waves.

\section{Acknowledgements}

First author SJ wish to acknowledge the support of IIT Madras through half-time research assistantship (HTRA).

\section{REFERENCES}

[1] Ahmad ReazKohansal, Hassan Ghassemi, (2010). A numerical modeling of hydrodynamic characteristics of various planing hull forms. Journal of Ocean Engineering, Vol.37, 498-510. https://doi.org/10.1016/i.oceaneng.2010.01.008

[2] Amin, N, Saeed, SM, (2016). RANS simulation of hydrofoil effects on hydrodynamic coefficients of a planing catamaran. Brodogradnja, Volume 67, Issue1, Page43-66.

[3] Bertorello C, Begovic E, Mancini S,(2015). Hydrodynamic performances of small size swath craft. Brodogr.Shipbuild. 66:1-22. 
[4] Brizzolara,S., (2003). "Hydrodynamic Analysis of Interceptors with CFD methods", Proc. Seventh International Conference on Fast Sea Transportation (FAST), Vol. 3.

[5] Carrica, P.M., Wilson R. V. and Stern, F. (2006). Unsteady RANS simulation of the ship forward speed diffraction problem, Computers \& Fluids, Vol.35, pp. 545-570. https://doi.org/10.1016/j.compfluid.2005.08.001

[6] Carrica, P.M., Wilson R. V., Noack R. W. and Stern, F. (2007).Ship motions using single-phase level set with dynamic overset grids, Computers \& Fluids, Vol.36, pp. 1415-1433. https://doi.org/10.1016/i.compfluid.2007.01.007

[7] CD-ADAPCO,(2014). STAR CCM, User's guide version 9.06.

[8] Cakici, F., Kahramanoglu, E. and Alkan, A.D. (2017).Numerical Prediction of Vertical Ship Motions and Added Resistance,The Royal Institution of Naval Architects, Vol 159. Part A4. Pp.393- 492 .https://doi.org/10.3940/rina.ijme.2017.a4.450

[9] Dong Jin Kim, Sun Young Kim, Young Jun You, Key Pyo Rhee, Seong Hwan Kim, YeonGyu Kim, (2013). Design of high-speed planing hulls for the improvement of resistance and sea keeping performance, International Journal of Naval Architecture and Ocean Engineering, 5:161 177 .https://doi.org/10.3744/JNAOE.2013.5.1.161

[10] De Luca F, Mancini S, Miranda S, Pensa C. (2016). An extended verification and validation study of CFD simulations for planing hulls. J Ship Res 60 (2):101-118. https://doi.org/10.5957/JOSR.60.2.160010

[11] Esteban.S, Giron-Sierra. J.M., B.De Andres-Toro, J.M.De la Cruz, (2005). Fast ships Models for Seakeeping improvement studies using Flaps and T-foils, Journal of Mathematical and Computer Modelling 41,1-24 .https://doi.org/10.1016/j.mcm.2004.09.002

[12] Ferziger,J. \& Peric,M., (2003). Computational Methods for Fluid Dynamics. 3rd Editio., Springer, Berlin. https://doi.org/10.1007/978-3-642-56026-2

[13] Fitriadhy.A and Amira Adam. N., (2017). Heave and pitch motions performance of a monotricat ship in head-seas, International Journal of Automotive and Mechanical Engineering, Volume 14, Issue 2 pp. 4243-4258 , June, .https://doi.org/10.15282/ijame.14.2.2017.10.0339

[14] Fu. T. C., Brucker K. A., Mousaviraad. S. M., Ikeda. C. M., Lee E. J., O’Shea. T. T., Wang. Z., Stern. F., and Judge. C. Q., (2018), An Assessment of Computational Fluid Dynamics Predictions of the Hydrodynamics of High-Speed Planing Craft in Calm Water and Waves, $32^{\text {nd }}$ Symposium on Naval Hydrodynamics, Hamburg, Germany, 5-10 August.

[15] Fridsma.G, (1969). A systematic study on the rough water performance of planing boats. Davidson Laboratory report 1275. .https://doi.org/10.21236/AD0708694

[16] Faltinsen Odd M., Sun Hui, (2011). Dynamic behaviour of semi-displacement and planing vessels in calm water and waves, IX HSMV, Naples, 25 - 27 May.

[17] Ghadimi.P, Abbas Dashtimanesh, YaserFarghoor, Maghrebi, (2013). Initiating a mathematical model for prediction of 6 DOF motion of planning crafts in regular waves.International Journal of Engineering Mathematics, Article ID 853793, 15 pages, https://doi.org/10.1155/2013/853793

[18] Ikeda, Y. and Katayama. T, (2000). Stability of high-speed craft. In: Contemporary Ideas on Ship Stability (D. Vassalos et al., Ed.). pp. 401-409. Elsevier Science Ltd. https://doi.org/10.1016/B978$\underline{008043652-4 / 50031-6}$

[19] ITTC, (2011). Practical guidelines for ship CFD applications (7.5-03-02-03). p. 1-18, Revision-01

[20] ITTC, (2011). Recommended Procedures and Guidelines, (7.5-02-07-02.1), Seakeeping Experiments, p. 1-22, Revision-04.

[21] Kohansal AR, Ghassemi H, Ghiasi M. (2010). Hydrodynamic characteristics of high-speedplaning hulls, including trim effects. Turk J Eng Environ Sci. 34:1e16.

[22] Lee, YG,Kim, C, Park, JH, Kim, H, Lee, Jin, B, (2019).Numerical simulations of added resistance in regular head waves on a container ship. Brodogradnja. Volume70. Issue2. https://doi.org/10.21278/brod70204

[23] Milton/Martin, (1976). Theoretical prediction of motions of high-speedplaning boats in waves, David W. Taylor Naval Ship Research and Development Center Y1S-15623-002, Bethesda, Maryland 20084.

[24] Ozdemir, Y.H. and Barlas, B. (2017). Numerical study of ship motions and added resistance in regular incident waves of KVLCC2 model. International Journal of Naval Architecture and Ocean Engineering, 9:2, pp 149-159. https://doi.org/10.1016/j.ijnaoe.2016.09.001 
[25] Pigazzini. R, F. De Luca, Pensa.C (2021). An experimental assessment of nonlinear effects of vertical motions of Naples systematic series planing hulls in regular waves. Applied Ocean Research. https://doi.org/10.1016/j.apor.2021.102546

[26] Rijkens.A.A.K, H. M. A. Cleijsen, J. A. Keuning, (2013). On the hydrodynamic performance of an improved motion control device for fast ships.

[27] Sebastiani Luca, Paola Gualeni, DaniloRuscelli Dario Bruzzone,GuidoRambaldi, Michele Viviani, (2008). A practical method for the prediction of planing craft motions in regular and irregular waves. Proceedings of the ASME 27th International Conference on Offshore Mechanics and Arctic Engineering, OMAE, June 15-20, Estoril, Portugal. https://doi.org/10.1115/OMAE2008-57946

[28] SuneelaJangam, AnanthaSubramanian.V, Krishnankutty.P. (2018). Computational Study on the Hydrodynamic Effects of Interceptors Fitted to Transom of Planing Vessel, 4th International conference in Ocean Engineering (ICOE), Springer, IIT Madras, Chennai, February 18-21.

[29] Sun Hui, Odd M. Faltinsen, (2010). Numerical study of planing vessels in waves, Journal of Hydrodynamics, $\quad$ supplement: $\quad 468-475, \quad$ DOI: $\quad 10.1016 /$ S1001-6058(09)60238-9. https://doi.org/10.1016/S1001-6058(09)60238-9

[30] Shuo Wang, YuminSu, Xi Zhang and Jinglei Yang, (2012). RANSE Simulation of High-speed Planing Craft in Regular Waves, Journal of Marine Sciences and Application.Vol 11: (4):447-452. https://doi.org/10.1007/s11804-012-1154-X

[31] Suneela.J, Krishnankutty.P, AnanthaSubramanian.V., (2020). Numerical investigation on the hydrodynamic performance of high-speed planing hull with transom interceptor, Journal of Ships and Offshore Structures. https://doi.org/10.1080/17445302.2020.1738134

[32] Savitsky,D., (1964). “Hydrodynamic Design of Planning Hull.” Marine Technology, Vol. 8, No.4 Oct.

[33] Tezdogan T., Demirel Y.K., Kellett P., Khorasanchi M., Incecik A. and Turan O. (2015). Full-scale unsteady RANS CFD simulations of ship behaviour and performance in head seas due to slow steaming, Ocean Engineering, 186-206. https://doi.org/10.1016/i.oceaneng.2015.01.011

[34] Tezdogan, T., Incecik, A. and Turan, O. (2016).Full-scale unsteady RANS simulations of vertical ship motions in shallow water, Ocean Engineering, 123: 131-145. https://doi.org/10.1016/j.oceaneng.2016.06.047

[35] Van Deyzen A, (2008). "A nonlinear mathematical model for motions of a planingmonohullIn head seas". 6th Int. Conf. on High Performance Marine Vehicles, Naples, Italy.

[36] Wang C.T, (1980). Wedge Effect OnPlaning Hulls, Journal of Hydronautics, Vol. 14, No.4. https://doi.org/10.2514/3.48182

[37] Xi H, Sun J.(2005)."Vertical plane motion of high-speedplaning vessels with controllable transom flaps: modelling and control", 16th Int. Triennial World Congress of International Federation of Automatic Control, Prague, Czech Republic. https://doi.org/10.3182/20050703-6-CZ-1902.01944

[38] Zarnick E, (1978). "A nonlinear mathematical model of motions of a planing boat in regular waves", Report No. 78/032, David Taylor Naval Ship Research and Development Center. https://doi.org/10.5962/bhl.title.47857

Submitted: 06.04.2021.

Accepted: 11.07.2021.
Jangam Suneela, suneelajangam4@gmail.com Department of Ocean Engineering

IIT Madras, Chennai-600 036

Prasanta Sahoo*, psahoo@fit.edu

Department of Ocean Engineering and Marine

Sciences, Florida Institute of Technology,

Florida, 32901,United States. 